\title{
Correction to: Human Organotypic Models for Anti-infective Research
}

\author{
Astrid Hendriks, Ana Rita Cruz, Elisabetta Soldaini, \\ Andrea Guido Oreste Manetti and Fabio Bagnoli
}

\section{Correction to:}

Chapter "Human Organotypic Models for Anti-infective Research" A. Hendriks et al., in:

Current Topics in Microbiology and Immunology, https://doi.org/10.1007/82_2018_130

The original version of this chapter was published with the copyright holder "Springer Nature Switzerland AG" and without open access. This has now been changed to the copyright holder "The Author(s)" and open access under the terms of the Creative Commons Attribution 4.0 International License (http:// creativecommons.org/licenses/by/4.0/). For further details see license information in the chapter.

The updated online version of this chapter can be found at https://doi.org/10.1007/82_2018_130

Current Topics in Microbiology and Immunology (2021) 430:265-265 